\title{
Atividade Residual de Diuron, Oxyfluorfen e Prometryne no CONTROLE DE Euphorbia heterophylla
}

\author{
Residual Activity of Diuron, Oxyfluorfen, and Prometryne for Euphorbia heterophylla Control \\ OLIVEIRA JR., R.S. ${ }^{2}$, CARNEIRO, J.C. ${ }^{3}$, CONSTANTIN, J. ${ }^{2}$, SANTOS, G. ${ }^{4}$, FRANCISCHINI, A.C. ${ }^{4}$ e \\ OLIVEIRA NETO, A.M. ${ }^{5}$
}

\begin{abstract}
RESUMO - As aplicações de herbicidas em pré-emergência têm por finalidade a obtenção da atividade residual no início do ciclo das culturas. Assim, o objetivo deste trabalho foi avaliar a atividade residual dos herbicidas diuron, oxyfluorfen e prometryne, aplicados isoladamente ou em misturas, no controle de Euphorbia heterophylla. Oito experimentos foram conduzidos em casa de vegetação, aplicando-se doses dos herbicidas ou das misturas aos 30, 20, 10 e 0 dias antes da semeadura da planta daninha (DAS). Com o diuron e prometryne, foram observados controles satisfatórios até 20 DAS nas doses a partir de 1,07 e 1,6 kg ha-1, respectivamente. Quanto ao oxyfluorfen, foi registrado um periodo residual inferior, obtendose controle minimo de $80 \%$ até 10 DAS nas doses a partir de $0,324 \mathrm{~kg} \mathrm{ha}^{-1}$. Em relação às misturas dos herbicidas, a mistura diuron+prometryne promoveu controle superior a $85 \%$ por períodos de até 30 dias, quando aplicada na menor dose (1+2 $\left.\mathrm{kg} \mathrm{ha}^{-1}\right)$, e de 20 dias, quando aplicada na dose de $2+1 \mathrm{~kg} \mathrm{ha}^{-1}$. Visando obter esse mesmo patamar de controle por 30 dias, foi necessário $1+0,288 \mathrm{~kg} \mathrm{ha}^{-1}$ da mistura diuron+oxyfluorfen. A mistura prometryne+oxyfluorfen apresentou um minimo de $80 \%$ de controle no periodo de 10 dias, quando utilizada a dose de $1+0,192 \mathrm{~kg} \mathrm{ha}^{-1}$
\end{abstract}

Palavras-chave: comportamento no solo, misturas de herbicidas, persistência.

\begin{abstract}
Pre-emergence herbicide applications are designed to obtain residual activity at the beginning of the crop cycle. The objective of this study was to evaluate the residual activity of diuron, oxyfluorfen, and prometryne, applied alone or in mixture, to control Euphorbia heterophylla. Eight experiments were conducted under greenhouse conditions, by applying herbicide doses or mixtures at 30, 20, 10, and 0 days before weed sowing (DBWS). With diuron and prometryne, satisfactory controls were observed at doses up to $20 \mathrm{DBWS}$, from 1.07 to $1.6 \mathrm{~kg} \mathrm{ha}^{-1}$, respectively. As for oxyfluorfen, a lower residual period was verified, with a minimum gaining control of at least $80 \%$ being obtained around $10 \mathrm{DBWS}$ at doses starting from $0.324 \mathrm{~kg} \mathrm{ha}^{-1}$. The herbicide mixtures diuron + prometryne promoted more than $85 \%$ control for up to 30 days, when applied at the lowest dose $\left(1+2 \mathrm{~kg} \mathrm{ha}^{-1}\right)$, and 20 days, when applied at $2+1 \mathrm{~kg} \mathrm{ha}^{-1}$.To obtain the same level of control for 30 days, it was necessary to apply $1+0.288 \mathrm{~kg} \mathrm{ha}^{-1}$ of oxyfluorfen + diuron mixture. The prometryne + oxyfluorfen mixture showed a minimum of $80 \%$ control within 10 days, when a dose of $1+0.192 \mathrm{~kg} \mathrm{ha-1}$ was applied.
\end{abstract}

Keywords: behavior in soil, herbicide mixtures, persistence.

\section{INTRODUÇÃO}

Herbicidas aplicados ao solo têm características que lhes conferem capacidade de controlar diferentes fluxos de emergência de plantas daninhas durante um período de tempo. Na cultura do algodão, o emprego de aplicações em pré-emergência é usual, sendo

Recebido para publicação em 23.6.2011 e aprovado em 12.3.2012.

2 Professor Associado, Núcleo de Estudos Avançados em Ciência das Plantas Daninhas, Universidade Estadual de Maringá NAPD/UEM, Dep. de Agronomia, Av. Colombo, 5790 87020-9000 Maringá- PR; ${ }^{3}$ Eng - -Agra ${ }^{\text {. }}$, Mestre em Proteção de Plantas; ${ }^{4}$ Eng$^{\mathrm{a}}-\mathrm{Agr}{ }^{\mathrm{a}}$., Mestranda do curso de Pós-Graduação em Agronomia - Proteção de Plantas, NAPD/UEM; ${ }^{5}$ Engo $^{-}$-Agr ${ }^{\circ}$., Doutorando do curso de Pós-Graduação em Agronomia - Proteção de Plantas, NAPD/UEM.

Planta Daninha, Viçosa-MG, v. 30, n. 3, p. 649-658, 2012 
essa modalidade muito utilizada em razão do lento crescimento inicial e da arquitetura da cultura. Essas aplicações visam o controle dos primeiros fluxos de plantas daninhas sem afetar o crescimento inicial da cultura. Com menor número de plantas inicial, tem-se como objetivo diminuir o número de aplicações posteriores em pós-emergência, com melhor controle das plantas remanescentes.

Sabe-se que, em função do longo ciclo e da necessidade de manter a cultura do algodão sem interferência das plantas daninhas até a colheita, uma única aplicação raramente é suficiente para permitir a colheita da cultura (Azevedo et al., 1988). Assim, a aplicação em pré-emergência é normalmente complementada por uma ou mais aplicações em pósemergência, em área total ou dirigidas nas entrelinhas.

Em se tratando da cultura do algodão, entre as principais alternativas de herbicidas utilizados em pré-emergência no início do ciclo estão diuron, oxyfluorfen e prometryne. Por sua vez, o leiteiro ou amendoim-bravo (Euphorbia heterophylla) destaca-se como uma das plantas daninhas de maior disseminação e importância nessa cultura. Um dos fatores que contribuem para o aumento dos problemas relacionados à presença do leiteiro em lavouras de algodão é o contínuo incremento da ocorrência de biótipos resistentes aos inibidores da ALS, uma vez que os herbicidas utilizados em pós-emergência da cultura se restringem a produtos com esse mecanismo de ação.

Na literatura são escassas as informações sobre o controle dessa planta daninha com o uso de herbicidas pré-emergentes na cultura do algodão, bem como estudos que abordem a capacidade de controle no período residual desses produtos, em relação a essa planta.

A atividade residual de herbicidas aplicados ao solo depende, em grande parte, das propriedades físico-químicas das moléculas, especialmente aquelas relacionadas aos processos de transporte e de degradação. O diuron apresenta baixa solubilidade em água (42 $\mathrm{mg} \mathrm{L}^{-1}$ a $25^{\circ} \mathrm{C}$ ) e é relativamente persistente em solos (meia-vida entre 90 e 180 dias), sendo a principal forma de dissipação da molécula a degradação microbiológica (Cullington et al., 1999). Os baixos valores de coeficiente de partição $\left(K_{d}\right)$ sugerem potencial de mobilidade no perfil do solo (Matallo et al., 2003), classificando-o como de moderado potencial de lixiviação.

Em estudo de cinética e sorção do diuron, observou-se que cerca de $85 \%$ do herbicida foi sorvido após 30 minutos de contato entre as moléculas e o solo (fase rápida). A sorção na fase lenta foi similar nos seis solos estudados, embora os teores de matéria orgânica fossem muito diferentes (Inoue et al., 2006). Diversos trabalhos mostraram que o comportamento sortivo do diuron apresenta relação positiva principalmente com os teores de matéria orgânica (Spurlock et al., 1994). Estudos de lixiviação em colunas de solo contendo Latossolo Vermelho (textura argilosa) e Neossolo Quartzarênico (textura arenosa) levaram à conclusão de que o diuron lixiviou através de $50 \mathrm{~cm}$, e o teor de matéria orgânica desses solos determinou a intensidade de lixiviação desse herbicida (Matallo et al., 2003).

O prometryne é um herbicida pouco lixiviado em solos de textura média e argilosos e lixiviável nos arenosos, com $K_{\mathrm{oc}}$ médio de $400 \mathrm{~mL} \mathrm{~g}^{-1}$ de solo. Sua degradação ocorre sobretudo por meio de microrganismos, sendo pouco sensivel às perdas por fotodecomposição e/ou volatilização. Nas doses recomendadas, apresenta persistência média de um a três meses em solos cultivados, dependendo da textura do solo, das condições climáticas e da dose (Senseman, 2007).

No caso do oxyfluorfen, a meia-vida no solo é estimada entre 30 e 40 dias, podendo apresentar atividade residual até seis meses após a aplicação. Sua degradação é essencialmente por fotólise, sendo mínima a degradação por microrganismos, o que faz com que em áreas com condições de umidade e sombreamento o período residual do produto seja mais prolongado. Depois de aplicado no solo, o oxyfluorfen é fortemente adsorvido pelos coloides, resistindo à lixiviação. A perda por fotodecomposição é mais lenta no solo do que na água (Rodrigues $\&$ Almeida, 2005). A temperatura tem grande importância na dissipação do oxyfluorfen, havendo grande incremento na taxa de desaparecimento desse herbicida acima de $25^{\circ} \mathrm{C}$ e dissipação mínima a $10{ }^{\circ} \mathrm{C}$ (Yen et al., 2003). 
Devido à importância do assunto e à carência de informações, este trabalho teve como objetivo avaliar a atividade residual dos herbicidas diuron, oxyfluorfen e prometryne, aplicados isoladamente ou em mistura dois a dois, visando ao controle de Euphorbia heterophylla.

\section{MATERIAL E MÉTODOS}

Os experimentos foram conduzidos em casa de vegetação, durante o período de dezembro de 2008 a janeiro de 2009. Foram utilizadas amostras de solo provenientes de uma litossequência localizada na Fazenda Experimental de Iguatemi, no município de Maringá-PR, coletado na profundidade de 0 a $20 \mathrm{~cm}$.

As amostras de solo foram submetidas a análises para determinar suas características químicas e granulométricas. Os resultados das análises evidenciaram as seguintes características: $\mathrm{pH}\left(\mathrm{H}_{2} \mathrm{O}\right)$ de 5,$2 ; 230 \mathrm{~g} \mathrm{~kg}^{-1}$ de argila; $80 \mathrm{~g} \mathrm{~kg}^{-1} \mathrm{de}$ silte; $370 \mathrm{~g} \mathrm{~kg}^{-1}$ de areia grossa; $320 \mathrm{~g} \mathrm{~kg}^{-1}$ de areia fina; e $11,43 \mathrm{~g} \mathrm{dm}^{-3} \mathrm{de}$ carbono orgânico. O solo do qual as amostras foram provenientes foi classificado como Argissolo Vermelho Distrófico (Embrapa, 1999), de textura franco-arenosa. Para todas as etapas deste trabalho, as unidades experimentais foram constituídas de vasos com capacidade volumétrica de $3 \mathrm{dm}^{-3}$ de solo.

Para avaliar o período da atividade residual dos herbicidas diuron, oxyfluorfen e prometryne, as aplicações foram feitas em diferentes periodos, de modo que correspondessem a certo número de dias antecedendo a semeadura de E. heterophylla, de acordo com metodologia previamente estabelecida (Marchiori Jr. et al., 2005). Foram avaliados períodos de tempo de 30, 20, 10 e 0 dias antes da semeadura (DAS) das plantas daninhas. Nas datas preestabelecidas para a aplicação dos herbicidas (30, 20, 10 e 0 DAS), as unidades experimentais foram irrigadas, com lâmina de água de 15 mm, 24 horas antes da aplicação. Portanto, todas as aplicações foram realizadas com solo úmido.

Na data de aplicação posterior, decorrido o número de dias estabelecidos, foi realizada a irrigação dos vasos a serem pulverizados, de acordo com o procedimento descrito anteriormente. Também foram irrigados todos os vasos que haviam recebido a aplicação dos tratamentos nas datas anteriores, novamente com lâmina de $15 \mathrm{~mm}$. Desse modo, os vasos com tratamentos referentes à aplicação dos herbicidas aos 30 DAS receberam quatro irrigações (total de $60 \mathrm{~mm}$ ); os vasos com aplicação aos 20 DAS, três irrigações (45 mm); os vasos com aplicação aos 10 DAS, duas irrigações (30 mm); e os vasos com aplicação em 0 DAS, uma irrigação $(15 \mathrm{~mm})$.

No dia 0, além da aplicação dos herbicidas, todos os vasos foram semeados cuidadosamente com a espécie em estudo, visando causar o mínimo distúrbio possivel ao solo. No momento da semeadura, em cada unidade experimental foram colocadas 30 sementes, na profundidade de 2 a $3 \mathrm{~cm}$. Depois de realizadas as aplicações e a semeadura, as unidades experimentais foram irrigadas sempre que necessário.

Para cada data de aplicação $(30,20,10$ e O DAS) foram conduzidos experimentos separados. Em cada um dos experimentos, os tratamentos foram arranjados num modelo hierárquico constituído pelas combinações de doses e herbicidas. As doses empregadas foram: $0 ; 0,700 ; 0,800 ; 0,900$; e 1,100 $\mathrm{kg} \mathrm{ha}^{-1}$ de diuron; 0; 0,096; 0,144; 0,288; e 0,336 kg ha${ }^{1}$ de oxyfluorfen; e 0; 0,550; 0,800; 1,050; e $2,050 \mathrm{~kg} \mathrm{ha}^{-1}$ de prometryne. O intervalo das doses utilizadas no presente trabalho foi estabelecido de acordo com ensaios preliminares.

Os experimentos de avaliação das misturas dos herbicidas foram conduzidos nas mesmas condições dos experimentos com diuron, oxyfluorfen e prometryne isolados em relação às unidades experimentais, semeadura da planta daninha e aplicação dos herbicidas. Os tratamentos foram constituídos pelas seguintes doses e misturas, em $\mathrm{kg} \mathrm{ha}^{-1}$ : diuron+ prometryne: $0+0,0,500+0,500,1,000+1,000$, $0,500+0,250,1,000+0,500,2,000+1,000$, $0,250+0,500,0,500+1,000,1,000+2,000$ e 2,000+2,000; diuron+oxyfluorfen: $0+0,1,000+$ $0,096,1,000+0,192,0,500+0,096,1,000+0,144$, $0,250+0,096,0,500+0,192,1,000+0,288 \mathrm{e}$ $2,000+0,288$; e prometryne+oxyfluorfen; $0+0$; $1,000+0,096 ; 1,000+0,192 ; 1,000+0,144$; 
$0,500+0,192 ; 1,000+0,288 ; 2,000+0,288$. Todos os experimentos foram conduzidos no delineamento experimental em blocos casualizados, com quatro repetições.

Nas aplicações dos herbicidas foi utilizado pulverizador costal pressurizado com $\mathrm{CO}_{2}$, com pressão constante de $35 \mathrm{lb} \mathrm{pol}^{-2}$, equipado com três pontas XR 110.02, espaçadas de $0,5 \mathrm{~m}$ entre si e posicionadas $0,5 \mathrm{~m}$ da superfície dos alvos, proporcionando um volume de aplicação de $200 \mathrm{~L} \mathrm{ha}^{-1}$ de calda. As condições no momento da aplicação dos tratamentos foram de velocidade do vento inferior a $5 \mathrm{~km} \mathrm{~h}^{-1}$, solo úmido, temperatura do ar de $23^{\circ} \mathrm{C}$ e umidade relativa de $87 \%$. A aplicação foi feita simultaneamente para todos os experimentos.

O controle de E. heterophylla foi avaliado por meio de escala percentual de notas aos 28 dias depois da semeadura (DDS). O valor $0 \%$ (zero) correspondeu à ausência de controle e $100 \%$ à morte das plantas, comparados à testemunha sem aplicação de herbicida. Decorridos 28 DDS, foi realizada a colheita da parte aérea do leiteiro, para determinar o acúmulo da massa seca da parte aérea. O material foi seco em estufa de ventilação forçada, com temperatura de $55^{\circ} \mathrm{C}$ até peso constante.

Os dados de massa seca foram corrigidos para valores percentuais, partindo-se do princípio de que as plantas que permaneceram sem aplicação de herbicida produziram 100\% de massa seca e que as demais produziram percentuais dessa massa, em decorrência da redução no crescimento imposta pelos herbicidas. Foi considerado controle satisfatório porcentagem de controle $\geq 80 \%$.

Os resultados da avaliação de controle de massa seca de $E$. heterophylla proporcionado pela aplicação dos herbicidas isolados foram inicialmente submetidos à análise de variância e, posteriormente, a análises de regressão para os diferentes períodos entre a aplicação e a semeadura da planta daninha. $\mathrm{Na}$ análise dos dados referentes às misturas herbicidas realizou-se análise de variância, e as médias de controle dos tratamentos com herbicidas foram comparadas com a testemunha sem aplicação pelo teste de Dunnett $(p<0,05)$, utilizando-se o programa estatístico SAEG 5.0 (SAEG, 1997).

\section{RESULTADOS E DISCUSSÃO}

\section{Atividade residual dos herbicidas utilizados isoladamente}

A atividade residual dos herbicidas diuron, oxyfluorfen e prometryne foi influenciada pelas doses empregadas e pelo periodo entre a aplicação e a semeadura da planta daninha. Embora o controle de E. heterophylla seja consistentemente maior com o aumento da dose dos três herbicidas, ocorreram diferenças importantes entre os períodos de tempo entre aplicação e semeadura da planta daninha e em relação ao controle máximo obtido (Figuras 1, 2 e 3).

Nas doses intermediárias de diuron avaliadas neste estudo, a aplicação em períodos de 30 ou 20 dias antecedendo a semeadura do leiteiro apresentou controle menor, em comparação com as aplicações realizadas aos $10 \mathrm{e}$ 0 DAS. Naquele caso, um platô de controle máximo se estabeleceu por volta de $83 \%$.

Controle aceitáve1 $(\geq 80,0 \%)$ de E. heterophylla foi observado com aplicações realizadas aos 20 DAS; para atingir esse nivel de controle foram necessárias doses de 1,07, 0,97 e $0,78 \mathrm{~kg} \mathrm{ha}^{-1}$ de diuron para aplicações feitas aos 20, 10 e O DAS, respectivamente. Por se tratar de uma espécie que se destaca entre as invasoras de maior disseminação e importância (Lorenzi, 2006), controles do leiteiro com atividade residual a partir de $60 \%$ podem ser importantes para supressão da planta daninha. Mesmo que esses niveis de controle possam não ser suficientes para prevenir o surgimento da interferência, ao retardar o desenvolvimento e diminuir os fluxos de emergência da planta daninha, há maior possibilidade de que aplicações realizadas em pós-emergência possam ser mais eficazes. Além disso, esses niveis de controle podem se tornar mais efetivos à medida que o controle cultural imposto pela cultura também passa a atuar.

Em relação à atividade residual do diuron, esperava-se um controle de E. heterophylla mais consistente, por se tratar de um herbicida com elevada persistência e mobilidade intermediária no solo (Peñaherrera-Colina et al., 2005). Um dos processos de degradação 

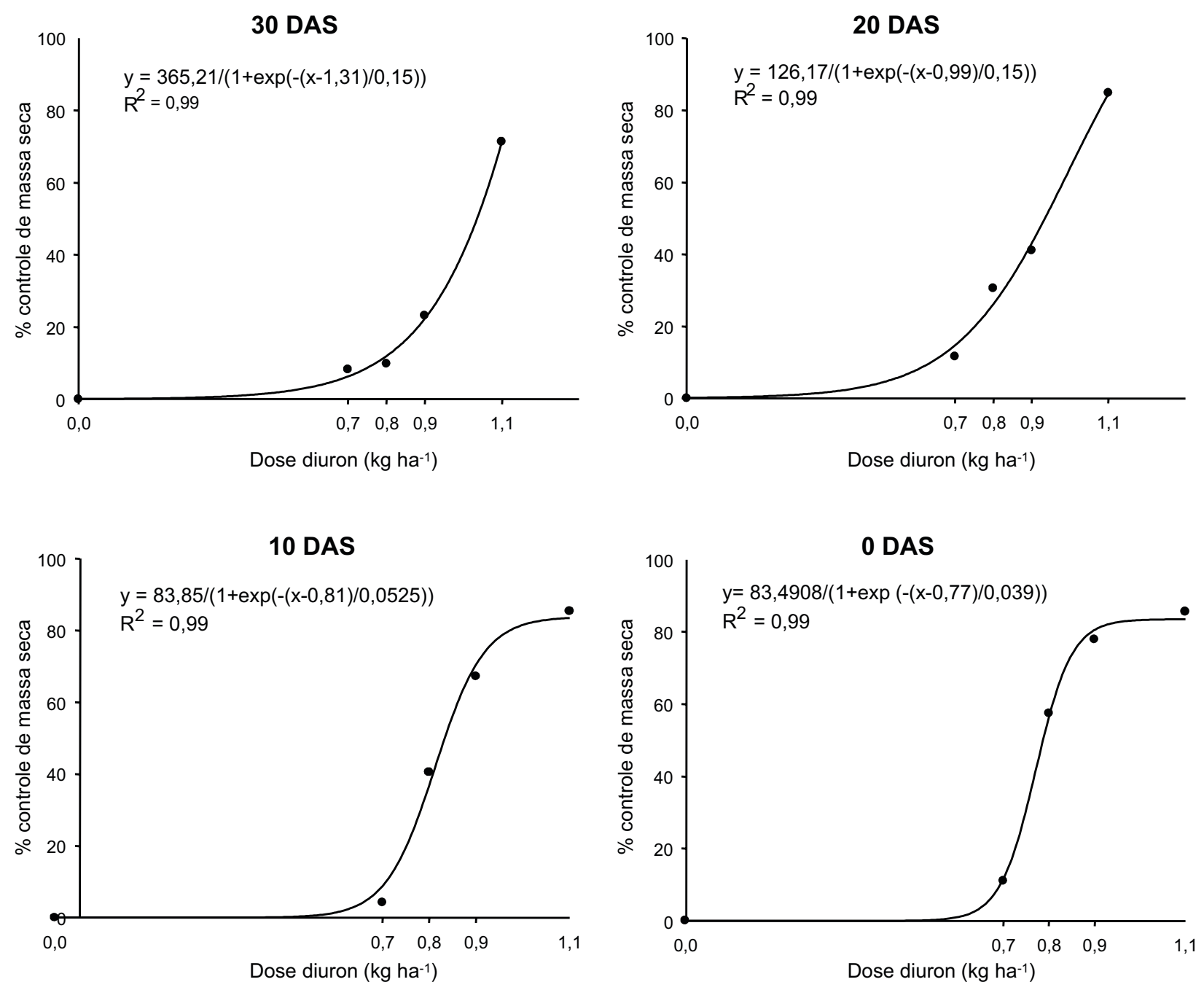

Figura 1 - Redução no acúmulo de massa seca proporcionada por doses crescentes de diuron aplicadas aos 30, 20, 10 e 0 dias antes da semeadura de Euphorbia heterophylla.

do diuron de maior importância é a degradação biológica, que está relacionada, principalmente, com os microrganismos presentes no solo. Pode-se supor que, nas condições em que o experimento foi conduzido, a atividade microbiana teve sua ação favorecida pelo fato de o ambiente de casa de vegetação apresentar diariamente elevadas temperaturas, sobretudo nos meses de dezembro a janeiro, período em que foi conduzido este estudo. Além da temperatura, os vasos foram irrigados de modo a manter continuamente teores de umidade adequados à plena atividade microbiana, sem a ocorrência de estresse hídrico, o que pode ter contribuído para diminuir a atividade residual de diuron.
O uso do prometryne gerou padrões de acúmulo de massa seca muito semelhantes aos observados com o uso do diuron (Figura 2). Ótimo controle do leiteiro foi observado quando a aplicação foi feita no dia da semeadura da planta daninha (0 DAS), aos 10 e aos 20 DAS, sendo controle satisfatório alcançado com doses a partir de 1,05, 1,26 e 1,58 $\mathrm{kg} \mathrm{ha}^{-1} \mathrm{de}$ prometryne aos 20, 10 e 0 DAS, respectivamente. Para aplicações realizadas aos 30 DAS, não se atingiu controle aceitável dentro das faixas estudadas neste trabalho.

As características do solo e do herbicida prometryne podem ter contribuído para a elevada atividade residual do herbicida na maior 
dose testada. O prometryne é um herbicida de dissociação básica - para o qual a retenção das moléculas é influenciada principalmente pelo teor de carbono e argila do solo - e que apresenta índice de sorção $\left(K_{\circ c}\right)$ entre 400 e $500 \mathrm{~mL} \mathrm{~g}^{-1}$ de solo (Oliveira Jr., 2007). Tratase, portanto, de herbicida com mobilidade intermediária em solos de textura média, o que pode aumentar a persistência da molécula no solo e contribuir para a atividade residual do herbicida.

Diferentemente do observado para diuron e prometryne, o oxyfluorfen promoveu controle eficiente de $E$. heterophylla aos 0 e 10 DAS (Figura 3). De acordo com as equações de regressão ajustadas, foi observados controle eficiente com doses a partir de $0,231 \mathrm{~kg} \mathrm{ha}^{-1}$ para aplicações aos 0 DAS e de $0,324 \mathrm{~kg} \mathrm{ha}^{-1}$ para aplicações aos 10 DAS.

A atividade residual de oxyfluorfen, quando empregado nas maiores doses testadas, mostrou-se inconsistente, não sendo suficiente para proporcionar controle satisfatório da planta daninha aos 20 e 30 DAS. Esses resultados demonstram que a atividade residual do oxyfluorfen depende da dose utilizada, devendo-se evitar o emprego de subdosagens.

O efeito residual de oxyfluorfen também foi estudado por Bezutte et al. (1995), utilizando
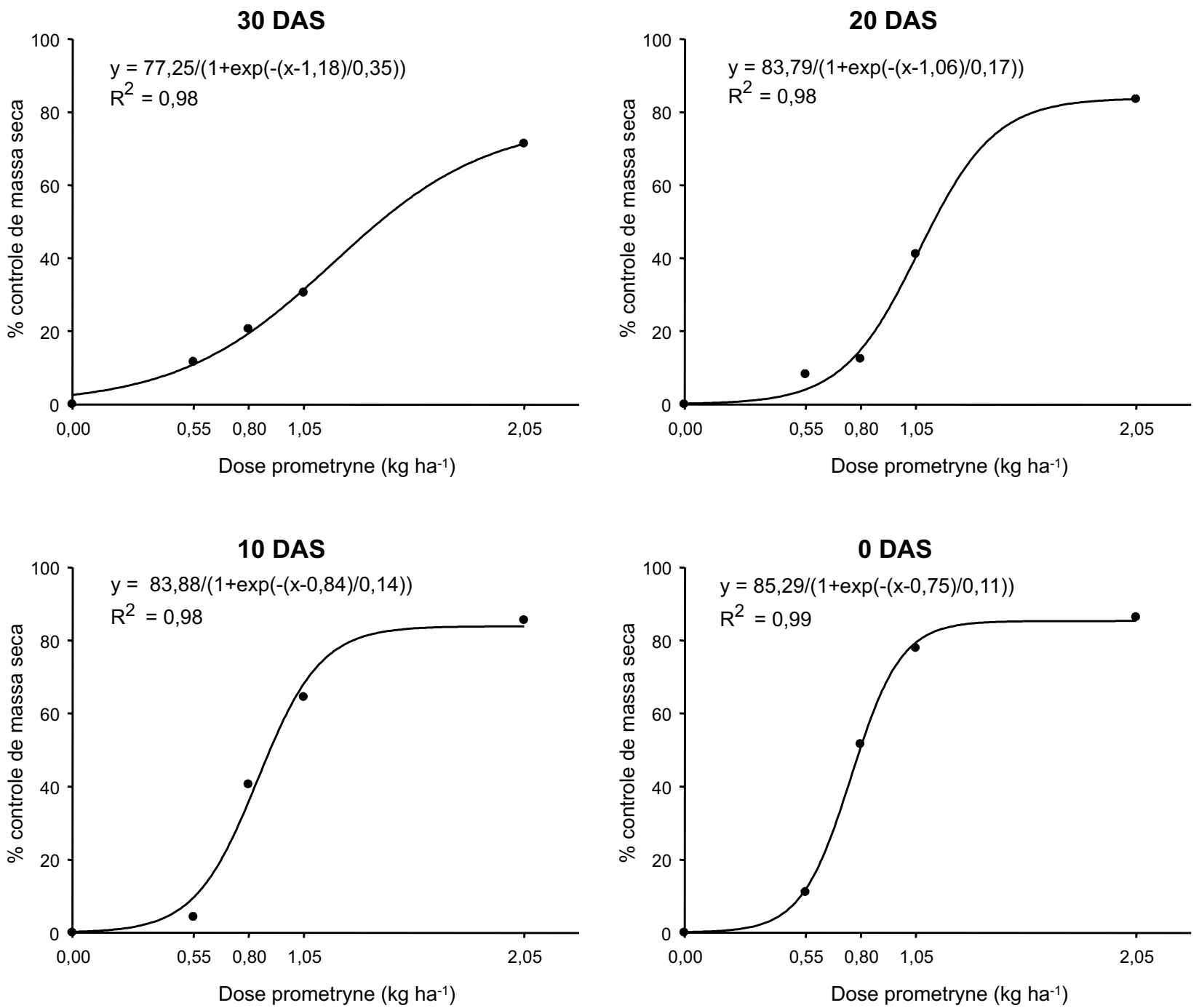

Figura 2 - Redução no acúmulo de massa seca proporcionada por doses crescentes de prometryne aplicadas aos 30, 20, 10 e 0 dias antes da semeadura de Euphorbia heterophylla. 
doses de 0,48 e $0,96 \mathrm{~kg} \mathrm{ha}^{-1}$. O herbicida promoveu controle satisfatório de Amaranthus retroflexus até $60 \mathrm{DAA}$, em experimento realizado em casa de vegetação. Em outro experimento, realizado em solo franco-siltoso e com $2,2 \%$ de matéria orgânica, verificou-se controle de $93,0 \%$ de Amaranthus rudis com aplicação em pré-emergência de $0,560 \mathrm{~kg} \mathrm{ha}^{-1}$ de oxyfluorfen (Falk et al., 2006).

O período de atividade residual encontrado no presente trabalho é inferior ao de Bezutte et al. (1995) e Falk et al. (2006); contudo, esses autores utilizaram doses muito maiores quando comparadas à dose máxima utilizada neste estudo. Além disso, diferentes espécies podem mostrar suscetibilidade distinta ao oxyfluorfen.

Em geral, verifica-se que a atividade residual dos herbicidas diuron, prometryne e oxyfluorfen é reduzida ao longo do tempo; as doses dos intervalos estudados proporcionaram efetiva atividade residual por periodos de até 20 dias, nas condições em que foi realizado este estudo.

Levando-se em conta um controle minimo de $60 \%$, verifica-se, aos 30 DAS, que o diuron proporcionou esse nivel de controle a partir de $1,07 \mathrm{~kg} \mathrm{ha}^{-1}$, e o prometryne, a partir de $1,6 \mathrm{~kg} \mathrm{ha}^{-1}$. No caso do oxyfluorfen, esse nível de controle só foi obtido no limite superior de doses avaliadas neste trabalho.
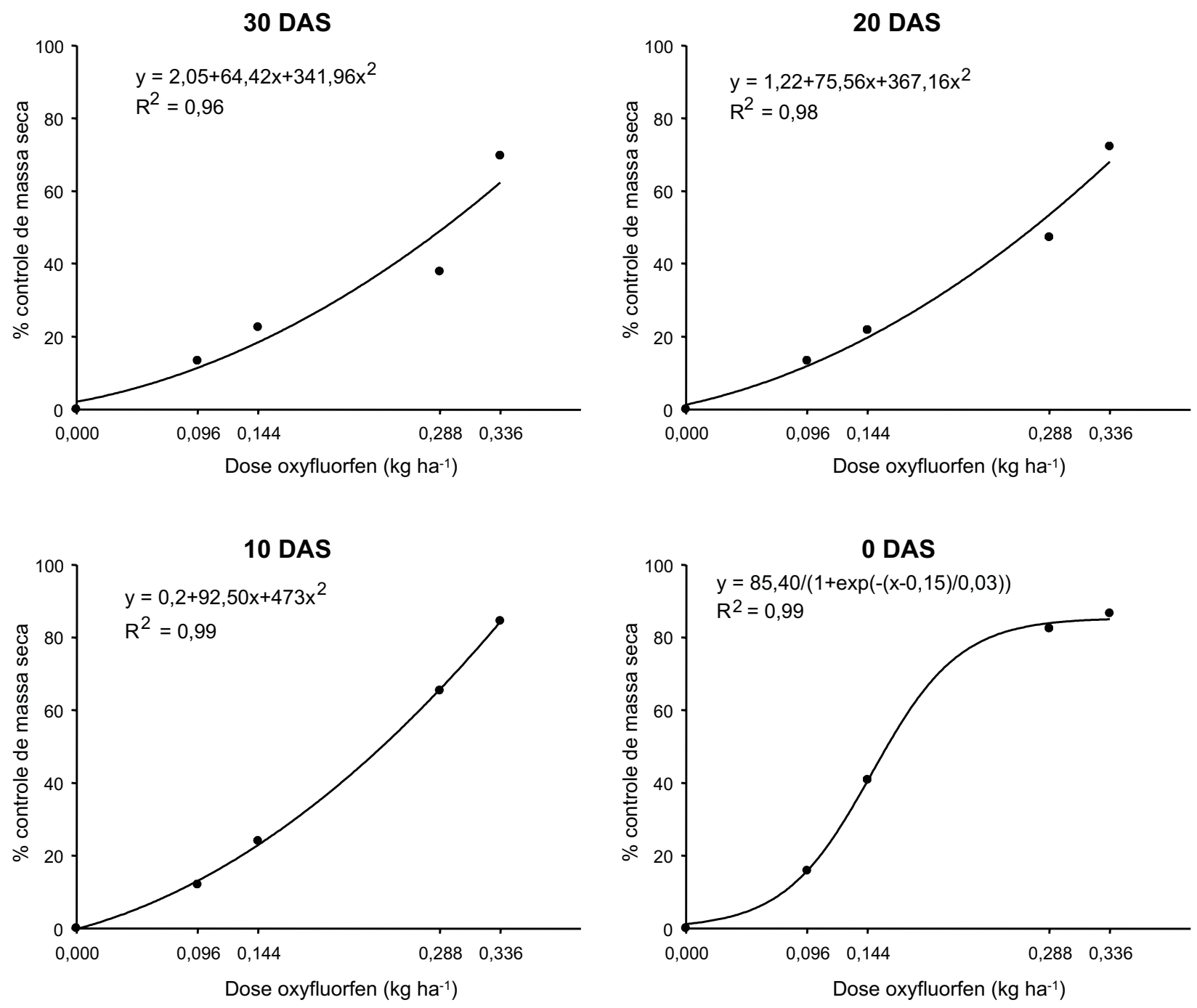

Figura 3 - Redução no acúmulo de massa seca proporcionada por doses crescentes de oxyflyorfen aplicadas aos 30, 20, 10 e 0 dias antes da semeadura de Euphorbia heterophylla. 


\section{Atividade residual das misturas de herbicidas}

Em todas as associações de diuron+ prometryne foi observada maior atividade residual quando doses maiores ou iguais a $1 \mathrm{~kg} \mathrm{ha}^{-1}$ de diuron e prometryne foram utilizadas (Tabela 1).

Ao comparar as porcentagens de controle visual em cada época de aplicação, pode-se verificar que, para aplicação realizada ao 0 DAS, verificou-se eficiência aceitável para as doses de $1+1 \mathrm{~kg} \mathrm{ha}^{-1}(85,5 \%), 2+1 \mathrm{~kg} \mathrm{ha}^{-1}$ $(97,5 \%), 1+2 \mathrm{~kg} \mathrm{ha}^{-1}(91,25 \%)$ e $2+2 \mathrm{~kg} \mathrm{ha}^{-1}$ $(97,5 \%)$ de diuron+prometryne.

No entanto, os niveis de controle diminuíram com o aumento entre o período da aplicação e a semeadura da planta daninha; aos 30 DAS, apenas as associações com as maiores doses de diuron e $2 \mathrm{~kg} \mathrm{ha}^{-1} \mathrm{de}$ prometryne proporcionaram controle eficiente de E. heterophylla.

Em resumo, visando obter controle do fluxo de emergência superior a $85 \%$ por períodos de 30 dias entre a aplicação dos herbicidas e a semeadura do leiteiro, foi necessário no mínimo $1 \mathrm{~kg} \mathrm{ha}^{-1}$ de diuron associado a $2 \mathrm{~kg} \mathrm{ha}^{-1}$ de prometryne. Para periodos de 20 dias, foram necessárias doses de no mínimo $2 \mathrm{~kg} \mathrm{ha}{ }^{-1}$ de diuron e $1 \mathrm{~kg} \mathrm{ha}^{-1}$ de prometryne. Em aplicações realizadas na data da semeadura do leiteiro, foi necessário aplicar no mínimo $1 \mathrm{~kg} \mathrm{ha}{ }^{-1}$ de diuron em associação com $1 \mathrm{~kg} \mathrm{ha}^{-1}$ de prometryne. Controles superiores a 95\% foram atingidos apenas com aplicações ao 0 DAS, com a associação de $2+1 \mathrm{~kg} \mathrm{ha}^{-1} \mathrm{e}$ $2+2 \mathrm{~kg} \mathrm{ha}^{-1}$ de diuron+prometryne, respectivamente.

Em relação ao controle proporcionado pela associação de diuron+oxyfluorfen, os melhores resultados foram observados ao 0 DAS. Houve controle de $91,25 \%$ e $95 \%$ nas combinações de $1+0,096$ e $2+0,288 \mathrm{~kg} \mathrm{ha}^{-1}$ de diuron e oxyfluorfen, respectivamente (Tabela 2).

A mesma tendência observada na associação entre diuron+prometryne também foi verificada na mistura diuron+oxyfluorfen. $\mathrm{Na}$ aplicação feita aos 10 DAS foi verificado controle efetivo do leiteiro nas combinações de $0,500+0,192,1+0,288$ e $2+0,288 \mathrm{~kg} \mathrm{ha}^{-1} \mathrm{de}$ diuron+oxyfluorfen, respectivamente.Contudo, aos 30 DAS apenas as doses de 1+0,288 e $2+0,288 \mathrm{~kg} \mathrm{ha}^{-1}$ dessa mistura de herbicidas proporcionaram controles aceitáveis de 86,5 e $89,5 \%$, respectivamente.

Portanto, para obter controle superior a $85 \%$ em aplicações realizadas aos 30 e aos 10 DAS, foram necessárias doses de no mínimo $1 \mathrm{~kg} \mathrm{ha}^{-1}$ de diuron em mistura com $0,288 \mathrm{~kg} \mathrm{ha}^{-1}$ de oxyfluorfen. Na aplicação realizada ao 0 DAS foram necessárias doses minimas de $1 \mathrm{~kg} \mathrm{ha}^{-1}$ de diuron associadas a $0,144 \mathrm{~kg} \mathrm{ha}^{-1}$ de oxyfluorfen. Controle superior a 95\% somente foi observado na aplicação ao

Tabela 1 - Porcentagens de controle (avaliação visual) de E. heterophylla aos 28 dias depois da semeadura (DDS), proporcionadas pelas misturas de diuron e prometryne, para aplicações realizadas aos 0, 10, 20 e 30 DAS. Maringá-PR - 2008/2009

\begin{tabular}{|c|c|c|c|c|c|}
\hline \multirow{2}{*}{ Herbicida } & \multirow{2}{*}{$\begin{array}{c}\text { Dose } \\
\left(\mathrm{kg} \mathrm{ha}^{-1}\right)\end{array}$} & \multicolumn{4}{|c|}{ Controle visual aos 28 DDS (\%) } \\
\hline & & $0 \mathrm{DAS}$ & 10 DAS & 20 DAS & 30 DAS \\
\hline Diuron + Prometryne & $(0,25+0,50)$ & $50,00(+)$ & $56,25(+)$ & 7,50 & $48,75(+)$ \\
\hline Diuron + Prometryne & $(0,50+0,25)$ & $63,75(+)$ & $58,75(+)$ & $40,00(+)$ & $56,25(+)$ \\
\hline Diuron + Prometryne & $(0,50+0,50)$ & $67,50(+)$ & 40,00 & 22,50 & $59,25(+)$ \\
\hline Diuron + Prometryne & $(0,50+1,00)$ & $68,75(+)$ & $58,75(+)$ & $41,25(+)$ & $53,75(+)$ \\
\hline Diuron + Prometryne & $(1,00+0,50)$ & $66,25(+)$ & $56,25(+)$ & $58,75(+)$ & $76,25(+)$ \\
\hline Diuron + Prometryne & $(1,00+1,00)$ & $85,50(+)$ & $68,75(+)$ & $45,00(+)$ & $60,00(+)$ \\
\hline Diuron + Prometryne & $(1,00+2,00)$ & $91,25(+)$ & $70,75(+)$ & $73,25(+)$ & $93,50(+)$ \\
\hline Diuron + Prometryne & $(2,00+1,00)$ & $97,50(+)$ & $75,00(+)$ & $92,50(+)$ & $68,75(+)$ \\
\hline Diuron + Prometryne & $(2,00+2,00)$ & $97,50(+)$ & $77,50(+)$ & $92,25(+)$ & $86,25(+)$ \\
\hline TEST & $(0,00+0,00)$ & 0,00 & 0,00 & 0,00 & 0,00 \\
\hline (DMS Dunett 5\%) & & 23,32 & 45,52 & 32,61 & 37,7 \\
\hline
\end{tabular}

* Médias seguidas de $(+)$ são significativamente superiores à testemunha, a $5 \%$ de probabilidade, pelo teste de Dunett. 
0 DAS, com $2 \mathrm{~kg} \mathrm{ha}^{-1}$ de diuron em mistura com $0,288 \mathrm{~kg} \mathrm{ha}^{-1}$ de oxyfluorfen.

No caso das aplicações de prometryne+ oxyfluorfen, nenhuma das combinações promoveu controle eficiente do leiteiro nas aplicações realizadas 20 ou 30 dias antes da semeadura. Nas aplicações feitas com menor intervalo de tempo entre a aplicação e a semeadura da planta daninha, os melhores resultados de controle foram obtidos com doses de 1 a $2 \mathrm{~kg} \mathrm{ha}^{-1}$ de prometryne combinadas com $0,288 \mathrm{~kg} \mathrm{ha}^{-1} \mathrm{de}$ oxyfluorfen ou de $1 \mathrm{~kg}$ ha ${ }^{1}$ com $0,192 \mathrm{~kg} \mathrm{ha}^{-1}$ dos respectivos herbicidas (Tabela 3).

De acordo com os resultados, pode-se concluir que a aplicação dos herbicidas diuron e prometryne de forma isolada promoveu controle satisfatório de E. heterophylla por periodos de até 20 dias com doses a partir de 1,07 e 1,6 $\mathrm{kg} \mathrm{ha}^{-1}$, respectivamente. Quanto ao oxyfluorfen, foi registrado um período de atividade residual inferior, obtendo-se controle mínimo de $80 \%$ por até 10 dias com doses a partir de $0,324 \mathrm{~kg} \mathrm{ha}^{-1}$. Todavia, com os três herbicidas avaliados, verificou-se supressão da planta daninha (controle $\geq 60,0 \%$ ) por períodos de até 30 dias quando se empregaram as maiores doses do intervalo estudado.

No tocante às misturas dos herbicidas, a mistura diuron+prometryne promoveu controle superior a $85 \%$ por períodos de 30 dias quando

Tabela 2 - Porcentagens de controle (avaliação visual) de E. heterophylla aos 28 dias depois da semeadura (DDS), proporcionadas pelas misturas de diuron e oxyfluorfen, para aplicações realizadas aos 0, 10, 20 e 30 DDS. Maringá-PR - 2008/2009

\begin{tabular}{|c|c|c|c|c|c|}
\hline \multirow{2}{*}{ Herbicida } & \multirow{2}{*}{$\begin{array}{c}\text { Dose } \\
\left(\mathrm{kg} \mathrm{ha}^{-1}\right)\end{array}$} & \multicolumn{4}{|c|}{ Controle visual aos 28 DDS (\%) } \\
\cline { 3 - 6 } & $(0,25+0,096)$ & $40,00(+)$ & $65,50(+)$ & $52,50(+)$ & 16,25 \\
\hline Diuron + Oxyfluorfen & $(0,50+0,096)$ & $83,75(+)$ & $59,50(+)$ & $38,75(+)$ & $57,50(+)$ \\
\hline Diuron + Oxyfluorfen & $(0,50+0,192)$ & $80,00(+)$ & $81,25(+)$ & $53,75(+)$ & $50,00(+)$ \\
\hline Diuron + Oxyfluorfen & $(1,00+0,096)$ & $91,25(+)$ & $75,00(+)$ & 26,25 & $47,50(+)$ \\
\hline Diuron + Oxyfluorfen & $(1,00+0,144)$ & $71,25(+)$ & $74,50(+)$ & $55,00(+)$ & $63,75(+)$ \\
\hline Diuron + Oxyfluorfen & $(1,00+0,192)$ & $68,75(+)$ & $66,25(+)$ & $60,00(+)$ & $41,25(+)$ \\
\hline Diuron + Oxyfluorfen & $(1,00+0,288)$ & $85,00(+)$ & $85,00(+)$ & $60,00(+)$ & $86,50(+)$ \\
\hline Diuron + Oxyfluorfen & $(2,00+0,288)$ & $95,00(+)$ & $84,50(+)$ & $77,75(+)$ & $89,50(+)$ \\
\hline Diuron + Oxyfluorfen & $(0,00+0,00)$ & 0,00 & $-10,00$ & 0,00 & 0,00 \\
\hline TEST & & 17,69 & 23,78 & 31,85 & 40,82 \\
\hline (DMS Dunett 5\%)
\end{tabular}

* Médias seguidas de $(+)$ são significativamente superiores à testemunha, a $5 \%$ de probabilidade, pelo teste de Dunett.

Tabela 3 - Porcentagens de controle (avaliação visual) de E. heterophylla aos 28 dias depois da semeadura (DDS), proporcionadas pelas misturas de prometryne e oxyfluorfen, para aplicações realizadas aos 0, 10, 20 e 30 DAS. Maringá-PR - 2008/2009

\begin{tabular}{|c|c|c|c|c|c|}
\hline \multirow{2}{*}{ Herbicida } & \multirow{2}{*}{$\begin{array}{c}\text { Dose } \\
\left(\mathrm{kg} \mathrm{ha}^{-1}\right)\end{array}$} & \multicolumn{4}{|c|}{ Controle visual aos 28 DDS (\%) } \\
\cline { 3 - 6 } & $(0,50+0,192)$ & $73,75(+)$ & $78,75(+)$ & $47,50(+)$ & $50,00(+)$ \\
\hline Prometryne + oxyfluorfen & $(1,00+0,096)$ & $62,50(+)$ & $70,00(+)$ & $57,50(+)$ & $55,00(+)$ \\
\hline Prometryne + oxyfluorfen & $(1,00+0,144)$ & $66,25(+)$ & $78,75(+)$ & $58,75(+)$ & $43,75(+)$ \\
\hline Prometryne + oxyfluorfen & $(1,00+0,192)$ & $86,25(+)$ & $81,25(+)$ & $51,25(+)$ & $55,00(+)$ \\
\hline Prometryne + oxyfluorfen & $(1,00+0,288)$ & $95,00(+)$ & $83,75(+)$ & $78,75(+)$ & $57,50(+)$ \\
\hline Prometryne + oxyfluorfen & $(2,00+0,288)$ & $87,00(+)$ & $76,75(+)$ & $76,50(+)$ & $61,25(+)$ \\
\hline Prometryne + oxyfluorfen & $(0,00+0,00)$ & 0,00 & 0,00 & 0,00 & 0,00 \\
\hline TEST & & 16,10 & 21,49 & 22,35 & 31,52 \\
\hline (DMS Dunett 5\%)
\end{tabular}

* Médias seguidas de (+) são significativamente superiores à testemunha, a 5\% de probabilidade, pelo teste de Dunett. 
aplicada em doses mínimas de $1+2 \mathrm{~kg} \mathrm{ha}^{-1} \mathrm{e}$ de 20 dias em doses de $2+1 \mathrm{~kg} \mathrm{ha}^{-1}$. Para obter esse mesmo patamar de controle por 30 dias, foi necessário $1+0,288 \mathrm{~kg} \mathrm{ha}^{-1}$ da mistura diuron+oxyfluorfen. Em relação a prometryne+ oxyfluorfen, um mínimo de $80 \%$ de controle foi obtido pelo período de 10 dias quando se utilizou a dose de 1+0,192 $\mathrm{kg} \mathrm{ha}^{-1}$.

\section{LITERATURA CITADA}

AZEVEDO, D. M. P. et al. Seletividade e eficiência de misturas de herbicidas no controle de plantas daninhas em algodoeiro herbáceo. Pesq. Agropec. Bras., v. 23, n. 8, p. $861-867,1988$.

BEZUTTE, A. J. et al. Eficiência do herbicida oxyfluorfen, quando veiculado ao papel, no controle de algumas espécies daninhas. Planta Daninha, v. 13, n. 1, p. 39-45, 1995

CULLINGTON, J. E.; Walker, A. Rapid biodegradation of diuron and other phenylurea herbicides by a soil bacterium. Soil Biol. Biochem., v. 31, n.1, p. 677-686, 1999.

EMPRESA BRASILEIRA DE PESQUISA AGROPECUÁRIA - EMBRAPA. Sistema brasileiro de classificação de solo. Rio de Janeiro, 1999.

FALK, J. S. et al. Protox-resistant common waterhemp (Amaranthus rudis) response to herbicides applied at different growth stages. Weed Sci., v. 54, n. 4, p. 793-799, 2006.

INOUE, M. H. et al. Sorption-desorption of atrazine and diuron in soils from southern Brazil. J. Environ. Sci. Health, Part B, v. 41, n. 3, p. 605-621, 2006.
LORENZI, H. Manual de identificação e controle de plantas daninhas: plantio direto e convencional, 6.ed. Nova Odessa: Instituto Plantarum, 2006. p. 339

MARCHIORI JR., O. et al. Efeito residual de isoxaflutole após diferentes períodos de seca. Planta Daninha, v. 23, n. 3, p. 491-499, 2005.

MATALLO, M. B. et al. Lixiviação dos herbicidas tebutiuron e diuron em colunas de solo. Pesticidas. R. Ecotoxicol. Meio Amb., v. 13, n. 1, p. 83-90, 2003.

OLIVEIRA JR., R. S. Comportamento dos herbicidas residuais no solo: relação entre parâmetros físico-químicos e atributos do solo. Maringá: EDUEM, 2007.

PEÑAHERRERA-COLINA, L. A. et al. Persistência biológica de ametryn, diuron e oxyfluorfen no solo. $\mathbf{C i}$. Agrotecnol., v. 29, n. 5, p. 980-985, 2005.

RODRIGUES, B. N.; ALMEIDA, F. S. Guia de herbicidas. 5.ed. Londrina: 2005. 591 p.

SISTEMA PARAANÁLISES ESTATÍSTICAS - SAEG versão 7.0, Viçosa, MG: Fundação Arthur Bernardes, 1997.

SENSEMAN, S. Herbicide handbook. 9.ed. Lawrence: Weed Science Society of America, 2007. 458 p.

SPURLOCK, F. et al. Thermodynamics of organic chemical partition in soil: 2. Nonlinear partition of substituted phenylureas from aqueos solution. Environ. Sci. Technol., v. 28, n.4., p. $996-1002,1994$.

YEN, J. H. et al. Dissipation of the herbicide oxyfluorfen in subtropical soils and its potential to contaminate groudwater. J. Ecot. Environ. Safety, v. 54, n. 2, p. 151-156, 2003. 